\title{
A Filosofia de Software Livre no Processo de Criação de Softwares Didáticos: uma faceta do projeto de emersão tecnológica de professores
}

\author{
Adriano Canabarro Teixeira** \\ Sérgio Roberto Kieling Franco ${ }^{* * *}$
}

\begin{abstract}
Resumo. Um dos aspectos potencializados na sociedade contemporânea pelo advento das Tecnologias de Informação e Comunicação, são as possibilidades de experiências de autoria baseadas na colaboração. Neste sentido, é urgente que se assuma a lógica das redes como ponto fundamental neste processo e como base para a criação de uma cultura equivalente, elemento fundamental para o exercício da cidadania. Assim, este artigo tem por objetivo apresentar algumas das aproximações existentes entre o processo de criação de softwares didáticos proposto no projeto de Emersão Tecnológica de Professores da Universidade de Passo Fundo e a filosofia do Software Livre, fenômeno social que é uma manifestação clara de uma cultura baseada na lógica das redes.
\end{abstract}

Palavras-chave. Inclusão digital, Filosofia do software livre, formação docente, software educacional

\begin{abstract}
. e of the potential aspects of the contemporary society, due to the advent of the Technology of Information and Communication, is the possibility of experiences of authorship based on collaboration. In this way, it is urgent to assume the logic of the nets as the basic point in this process and as base for creation of an equivalent culture, basic element for the exercise of the citizenship. Thus, this article has the objective to present some of existing approaches between the process of creation of didactic software considered in the project of Technological Emersion of Professors in the University of Passo Fundoand the philosophy of Free Software, social phenomenon that is a clear manifestation of a culture based on the logic of the nets.
\end{abstract}

Key-words: Digital inclusion, Free software philosophy, teacher education, educational software

\footnotetext{
* Artigo construído a partir das atividades de pesquisa realizadas no doutorado em Informática na Educação da Universidade Federal do Rio Grande do Sul.

** Professor pesquisador, Doutor em Informática na Educação, Instituto de Ciências Exatas e Geociências Universidade de Passo Fundo (UPF), teixeira@upf.br.

*** Professor Pesquisador, Doutor em Educação. Programa de Pós-Graduação em Informática na Educação Universidade Federal do Rio Grande do Sul (UFRGS), sergio.franco@ufrgs.br V. $4 \mathrm{~N}^{\circ} 1$, Julho, 2006
} 


\section{A sociedade contemporânea}

Vivemos uma época sob o desenvolvimento vertiginoso das Tecnologias de Rede (TR), onde os avanços tecnológicos são visíveis e se confundem com a vida cotidiana dos indivíduos ampliando as possibilidades de trocas de informações e favorecendo o desenvolvimento de experiências baseadas em comunicação e colaboração.

Muito embora se reconheçam os interesses de mercado em fomentar o desenvolvimento tecnológico e a ampliação do acesso às TR e que, mesmo assim tal realidade é ainda distante da grande maioria da população, neste artigo se busca aprofundar e propor reflexões, especificamente acerca dos conceitos que possibilitaram tal conectividade, abertas a novas apropriações uma vez que são anteriores aos produtos técnicos e à sua utilização préviamente definida.

\subsection{A perenidade das redes e a urgência de uma cultura equivalente}

Mais antigo do que a própria humanidade, o conceito de rede se apresenta como ubíquo, contemporâneo e urgente. Ubíquo, na medida em que está presente no cerne de fenômenos biológicos e sociais; contemporâneo uma vez que o advento das redes de computadores expôs ao extremo suas características e potencialidades; e urgente para uma sociedade imersa em uma cultura de passividade, recepção e reprodução, ainda baseada na distribuição broadcast de informações, característica básica das mídias tradicionais.

A fim de refletir sobre o funcionamento e potencialidade das redes, utiliza-se como ponto de partida os conceitos de Hipertexto e de Cibercultura, na medida em que trazem em sua gênese a lógica e a marca das estruturas reticulares.

O primeiro conceito, aprofundado por Pierre Lévy em 1993, está intimamente relacionado à dinâmica das redes e, segundo o autor, "não dá conta somente da comunicação, mas dos processos sociotécnicos que, assim como vários outros fenômenos têm uma forma hipertextual".

Visando apresentar a forma como uma trama hipertextual se organiza, Lévy propõe seis princípios: $\mathrm{O}$ da metamorfose, o da heterogeneidade, o da multiplicidade e de encaixe das escalas, o da exterioridade, o da topologia, e finalmente, o da mobilidade dos centros. O conjunto dos princípios aponta essencialmente para a impossibilidade da existência de uma rede hipertextual na ausência de nós em constante movimento comunicacional.

O segundo conceito adotado nas reflexões sobre o funcionamento das redes foi aprofundado por André Lemos, que ao tratar da Cibercultura a define como "forma sócio-cultural que emerge da relação simbiótica entre a sociedade, a cultura e as novas tecnologias" (2003). Fundamentalmente, ela busca romper com a dinâmica informacional baseada em relações do tipo Um para Todos, potencializando as trocas Todos para Todos e possibilitando que cada indivíduo seja concomitantemente emissor e receptor de informações e sentidos.

Tal organização sócio-cultural está baseada em três leis específicas, as Leis da Cibercultura. Na primeira lei, denominada Lei da Reconfiguração, o autor aponta para a necessidade de reconfigurar práticas, modalidade mediáticas, espaços, sem a substituição de seus respectivos antecedentes; a lei seqüente, caracterizada pela Liberação dos pólos de emissão, sugere que as diversas manifestações sócio-culturais contemporâneas representam vozes e discursos anteriormente reprimidos pela edição da informação pelos complexos comunicacionais de massa; por fim, a lei da conexão 
generalizada, destaca a evolução do computador pessoal desconectado $(\mathrm{CP})$, para o computador conectado à rede $(\mathrm{CC})$, e finalmente o computador conectado móvel $(\mathrm{CCm})$ (Lemos, 2003).

Nestas diretivas, assim como nas propostas por Lévy, é possível detectar a estreita interdependência existente entre a rede e a ação de seus nós, em uma dinâmica comunicacional que permite novas formas de apropriação das tecnologias contemporâneas, e que, independente de sua intencionalidade geradora, possibilitam aos indivíduos e grupos a que pertencem, organizarem-se e mobilizarem-se no sentido de ampliar seus horizontes de interação e de ação, demandando uma mudança de postura aos indivíduos a fim de poderem transitar e participar desta realidade comunicacional.

Além da natural e forte relação existente entre os dois conceitos apresentados, deseja-se destacar algumas aproximações que interessam particularmente para a proposta deste artigo através da abstração de alguns de seus elementos centrais, e que, posteriormente auxiliam na definição do conceito de redes.

Tabela 1. Processo reflexivo para o estabelecimento do conceito de Rede

\begin{tabular}{|c|c|c|c|c|}
\hline Hipertexto & $\begin{array}{ll}\text { Leis } & \text { da } \\
\text { Cibercultura }\end{array}$ & Ponto convergente & Processo reflexivo & Característica \\
\hline $\begin{array}{l}\text { Da mobilidade } \\
\text { dos centros }\end{array}$ & $\begin{array}{l}\text { Liberação dos } \\
\text { pólos de emissão }\end{array}$ & $\begin{array}{l}\text { Necessidade/possibilidade } \\
\text { de uma postura ativa de } \\
\text { cada nó da rede. }\end{array}$ & $\begin{array}{l}\text { A rede só existe em função da } \\
\text { atividade/acessibilidade de seus } \\
\text { nós. }\end{array}$ & Atividade \\
\hline $\begin{array}{l}\text { Da } \\
\text { multiplicidade } \\
e \text { de encaixe } \\
\text { das escalas }\end{array}$ & $\begin{array}{l}\text { Conexão } \\
\text { generalizada }\end{array}$ & $\begin{array}{l}\text { Ampliação ou redução das } \\
\text { redes através de nós } \\
\text { permanentemente } \\
\text { disponíveis e que se } \\
\text { conectam a outros nós ou } \\
\text { redes. }\end{array}$ & $\begin{array}{l}\text { A composição de uma rede é } \\
\text { complexa e indeterminada em } \\
\text { função das diferentes ações e } \\
\text { elementos postos em movimento } \\
\text { para o(s) processo(s) corrente(s). }\end{array}$ & Complexidade \\
\hline $\begin{array}{l}\text { Da } \\
\text { metamorfose }\end{array}$ & Reconfiguração & $\begin{array}{l}\text { Dinâmica impressa à rede } \\
\text { em função da ação de seus } \\
\text { nós, dos processos } \\
\text { correntes e das novas } \\
\text { requisições feitas à } \\
\text { estrutura reticular. }\end{array}$ & $\begin{array}{l}\text { Em função da multiplicidade de } \\
\text { processos e de elementos } \\
\text { envolvidos nos movimentos } \\
\text { comunicacionais suportados pela } \\
\text { estrutura reticular, esta está em } \\
\text { constante atividade e cada } \\
\text { processo demanda diferentes } \\
\text { composições e configurações à } \\
\text { rede. }\end{array}$ & Dinamicidade \\
\hline
\end{tabular}

A partir desta contextualização, pode-se conceituar Rede como uma estrutura complexa, dinâmica e aberta, cuja condição primeira para existência é a ação dos nós que a formam e que, ao construir suas próprias formas de apropriação e de ação sobre a trama, a modificam e são modificados por ela ${ }^{1}$.

\subsection{A questão da autoria na dinâmica das redes}

O que se coloca em jogo na Sociedade Contemporânea, e também como fundamental na lógica das redes, é a necessidade de assumir o papel de nó na trama em uma perspectiva contrária à dinâmica de distribuição, apropriando-se das características e potencialidades das redes e das tecnologias que a suportam. Procedimento que segundo Lemos remete a "novas potencialidades libertadoras para os cyborgs interpretativos", elevando-os para a dimensão de netcyborgs (2002), seres que através

1 Salienta-se que tal conceituação não tem o objetivo de constituir-se em um novo conceito de rede, mas de representar uma sistematização conceitual baseada na abstração dos pontos principais dos conceitos e reflexões feitas sobre Hipertexto e Cibercultura.

2 " $[$...] o cyborg interpretativo e constitui pela influencia dos mass media, coagido que é pelo poder da televisão e do cinema. Assim, a cultura de massa e do espetáculo nos fez cyborgs interpretativos" (LEMOS).

V. $4 \mathrm{~N}^{\mathrm{o}} 1$, Julho, 2006 
de uma postura ativa anulam gradativamente o controle das mídias de massa e se organizam a partir de conexões Todos para Todos.

Reconhece-se que tal processo acontece gradualmente, através de experiências de autoria onde, a partir das modificações impressas pelo sujeito na rede de significações na qual se encontra, ele próprio seja reconfigurado e possa sentir-se capaz de, a partir do aprimoramento das habilidades envolvidas e da reflexão crítica sobre suas manifestações criativas, experimentar autorias mais complexas e significativas para ele e para a trama hipertextual.

Neste sentido, ao refletir sobre o papel do autor, Maraschin o define como "processualidade, não tendo um caráter definitivo, finito, mas que se relança a cada passo" (2000) e que, segundo a lógica das redes, é caracterizado pela interrupção da postura unidirecional e linear tradicional na busca de uma liberdade criativa, assumindose como um nó ativo da rede de sentidos, subvertendo o paradigma da recepção instituído através de experiências de autoria baseadas no protagonismo, na criticidade, na horizontalidade e na liberdade.

Propostas estas reflexões, destaca-se a urgência do desenvolvimento de uma cultura de rede entendida como um conjunto complexo de sentidos, concepções e condutas fundamentais aos indivíduos na sociedade contemporânea, baseado na lógica das redes e caracterizado principalmente pelo rompimento do paradigma de recepção e reprodução em uma dinâmica permanente de construção e manutenção de fluência tecno-contextual, processo dinâmico e provisório que se renova e aprimora na ação e na interação dos nós sobre e na rede de sentidos e suas interconexões.

\section{A dimensão reticular do processo de autoria}

Dadas as características das redes, amplia-se a necessidade e a possibilidade de autoria para a dimensão de Autoria Colaborativa, onde os indivíduos constroem processos horizontais e comunicativos, valorizando a dimensão colaborativa da aprendizagem, propiciada por momentos de ampla reflexão e discussão, contribuindo em última análise para o aprimoramento da rede e de seus nós.

Ao tratar de autoria colaborativa, possível também na ausência de tecnologias de rede mas potencializada pelas suas características, pode-se defini-la como um processo onde cada nó da rede é co-responsável pelo o que está acontecendo na trama criativa em determinado momento, transitando em uma ordem antagonicamente caótica que acaba por culminar em um processo extremamente dinâmico, produtivo e auto-regulado.

Nesta dinâmica, o fenômeno Software Livre figura como o principal exemplo de autoria colaborativa, na medida em que conecta pessoas em todos os lugares do mundo com o objetivo de, num processo de respeito mútuo e de atividade conjunta, propiciar a circulação e o avanço do conhecimento.

\subsection{A filosofia do software livre como manifestação de cultura de rede}

Embora seja um fenômeno em crescente evidência na atualidade, é preciso que se faça um resgate do conceito de Software Livre e da filosofia que o norteia a fim de que se desenvolva o raciocínio referente à relação existente entre ele, e o processo de construção de softwares didáticos proposto e vivenciado no projeto de emersão tecnológica de professores.

Referindo-se ao movimento Software Livre, Silveira afirma que é "baseado no princípio do compartilhamento do conhecimento e na solidariedade praticada pela inteligência coletiva conectada na rede mundial de computadores" (2003). Tal premissa 
está clara em seus elementos definidores onde a idéia de liberdade é fortemente presente e transcende aspectos técnicos. Tais elementos são:

A liberdade de executar o programa, para qualquer propósito; A liberdade de estudar como o programa funciona e adaptá-lo para as suas necessidades; A liberdade de redistribuir cópias de modo que se possa coloca-lo a serviço de outras necessidades; e a liberdade de aperfeiçoar o programa e liberar os seus aperfeiçoamentos de modo que toda a comunidade se beneficie (PSL, 2005).

Em uma análise mais ampla, tais dimensões representam a liberdade de experimentar novas e contextualizadas soluções e parcerias para propósitos específicos, sempre em uma perspectiva de aperfeiçoamento e de colaboração. Neste sentido, Lemos afirma que "além da forma cooperativa de trabalho, trata-se de buscar adicionar, modificar o que foi dito, escrito, gravado, sem a lógica proprietária, sem a dinâmica da acumulação e do segredo" (2004). Portanto, mais importante do que o fenômeno técnico é a filosofia que o fundamenta e dá significação.

Assim, assumir a filosofia do Software Livre é aceitar o desafio de ser autor, reconhecendo-se como um nó de uma rede colaborativa, que através de experiências reflexivas de autorias e co-autorias, se refina e se aperfeiçoa em uma dinâmica de autonomia provisória, pautada pela colaboração com os demais nós a fím de se harmonizar com a dinâmica da rede e suas reconfigurações, envolvendo-se em uma espiral de apropriações e re-apropriações de conceitos, técnicas e possibilidades.

\section{O projeto de emersão tecnológica de professores}

O projeto de Emersão Tecnológica, realizado em 2004 na Universidade de Passo Fundo com alunos dos cursos de licenciatura, constituiu-se em um processo de formação de professores fundamentado na lógica das redes com vistas ao desenvolvimento de uma cultura equivalente, onde cada um pôde reconhecer-se como nó da trama e responsável por ela, vivenciando momentos de autoria reflexiva e de experimentação ${ }^{3}$.

Uma vez que o projeto foi desenvolvido a partir da lógica das redes, portanto aberto à ação e à participação direta dos nós que o compunham, algumas atividades já haviam sido previstas em sua necessidade, porém não em seu formato, a fim de que os sujeitos pudessem experimentar uma autoria contextualizada às suas demandas e necessidades, que fomentasse a reflexão, que possibilitasse a criação de uma rede colaborativa, e que culminasse na proposta e na produção de algo que, em representando o resultado prático e imediato do processo vivenciado, contribuísse para a o desenvolvimento de uma cultura de rede nos sujeito-autores.

Neste sentido, a decisão do grupo por construir softwares didáticos entendidos como estruturas hipermidiais não necessariamente conectadas a uma estrutura técnica de rede, mas abertos ao exercício de autoria, contemplava as expectativas da pesquisa, uma vez que tão importante quanto utilizar e colaborar no aperfeiçoamento de um determinado software é compreender e apropriar-se do processo criativo ${ }^{4}$.

Dentre as diversas manifestações de cultura de rede e em função da intencionalidade e limites do presente texto, deseja-se explorar especificamente aquelas que se referem especificamente ao processo de autoria baseado na filosofia de Software Livre e suas implicações na construção dos softwares didáticos pelos sujeitos envolvidos.

\footnotetext{
Maiores informações sobre a experiência em Teixeira (2004) e Teixeira (2005).

Maiores informações sobre a metodologia de construção em Teixeira e Brandão (2003). V. $4 \mathrm{~N}^{\circ} 1$, Julho, 2006
} 


\section{A filosofia do software livre no processo de construção de softwares didáticos}

Durante o processo de construção dos softwares, os sujeitos vivenciaram momentos de autoria individual e colaborativa, de criação e de descoberta, sendo continuamente impelidos a refletir sobre suas produções e de seus colegas, livres para expressar através de seus projetos de software didático, aquilo que melhor pudesse refletir seus objetivos.

A fim de melhor analisar a relação existente entre tal processo e a filosofia de Software Livre, opta-se pelo estabelecimento de duas dimensões de análise, a primeira é baseada na relação direta entre a experiência de construção dos softwares didáticos e as Leis do Software Livre, enquanto que a segunda, mais significativa, relaciona tal vivência criativa à filosofia desta modalidade de software, enfatizando sua contribuição do processo na criação de cultura de rede dos envolvidos.

Com relação à primeira dimensão, referente à construção dos softwares didáticos enquanto processo intimamente relacionado às Leis do Software Livre, registra-se que embora tenham sido desenvolvidos a partir de um ambiente proprietário, a forma de apropriação da tecnologia e a dinâmica de construção dos softwares contemplaram as liberdades previstas aos Softwares Livres, como explicitado a seguir.

À medida que cada um tinha a possibilidade de criar um software didático para uma demanda e contexto específico, conseqüentemente possuíam a liberdade para executá-lo em qualquer situação e com qualquer propósito, consolidando-se a primeira liberdade.

No que se refere à liberdade de estudar e alterar o programa em função de necessidades específicas, a estrutura aberta e hipermidial construída a partir de uma ferramenta comum e visual, possibilitou o estabelecimento de momentos de parceria no desenvolvimento dos softwares didáticos, bem como de troca de softwares entre os sujeitos do processo a serem utilizados e alterados para outras realidades.

Referindo-se à liberdade de redistribuir cópias, destaca-se que uma vez criados em função de necessidades específicas, à medida em que os softwares eram construídos podiam ser distribuídos entre os demais componentes do grupo para que pudessem não somente auxiliar na sua construção, mas também utilizá-los nos ambientes a que tinham acesso.

Finalmente, a condição de autores e co-autores assumida pelos sujeitos, os habilitava a melhorar seus próprios projetos e contribuir com a melhoria dos softwares dos demais, seja agindo diretamente sobre eles ou compartilhando as descobertas feitas em seus próprios projetos didáticos, contemplando desta forma a quarta liberdade do Software Livre: aperfeiçoar e liberar os aperfeiçoamentos.

Como exemplo da manifestação destas liberdades durante o processo, e também como manifestação de cultura de rede, é possível relatar dois eventos significativos. $\mathrm{O}$ primeiro se refere ao estabelecimento de autoria colaborativa com que uma das participantes do projeto atuou no desenvolvimento dos softwares de dois colegas em função da impossibilidade destes continuarem a participar das atividades do grupo.

O segundo, extrapolando o alcance da rede de significações do projeto, na medida em que um dos sujeitos-autores vislumbrou a possibilidade de realizar a construção de softwares didáticos junto aos alunos da escola onde trabalhava como forma de criar um contexto onde fosse possível a construção do conhecimento em um movimento de co-autoria com e entre os alunos, como expressou no depoimento abaixo: 
Ah para mim foi ótimo, porque eu posso utilizar o que eu aprendi lá dentro com vocês, agora na sala de aula para mim, até para mostrar para os alunos que eles também podem criar alguma coisa, que eles também podem ir atrás disso, que tem outros recurso (Tac4402) ${ }^{5}$.

A segunda dimensão se refere ao exercício da autoria e co-autoria vivenciada pelo grupo no processo já a partir da definição da atividade prática. Neste sentido, enquanto autores possuíam total autonomia sobre seus projetos, constantemente foram (I) requisitados a refletir sobre eles, sozinhos ou colaborativamente, (II) modificando, questionando e detectando necessidade de melhorias, (III) reconfigurando a rede de significações na qual estavam inseridos através da conexão a novos nós internos ou não à rede formada, (IV) retomando constantemente reflexões acerca das potencialidades das TR e da importância em descobrir-se capaz de fazer diferença no contexto do qual faziam parte. O conjunto de depoimentos abaixo ilustra este percurso:

(I) [...] havia pessoas das Letras, pessoas da Matemática, pessoas da Psicologia, pessoas ligadas à educação e que ali estavam criando, vendo formas divertidas e criativas de você trabalhar aquele mesmo assunto (Dan6208).

(II) E a maneira que eu fiz o meu software, do jeito que eu fiz, agora que eu sei um pouco mais, que eu aprendi um pouco mais até na faculdade, em ver conteúdos essas coisas, eu mudaria o tipo de atividade que eu coloquei lá (Tac4402).

(III) [...] que os nossos colegas possam trabalhar em cima daquilo, e não só abrir e ficar olhando e não servir para nada senão aquilo ... e eu já fui atrás de professores de Português, porque eu não atuo eu quero saber o que precisa, o que eles acham que está sendo dificuldade, eles querem colaborar comigo eu pesquisei em outras universidades sobre isso e eu quero que o meu seja usado e não esteja jogado na gaveta (Mar0624).

(IV) [...] hoje em dia nós já temos capacidade eu acho não somos experts, mas temos capacidade construir um software e esse desafio está dentro nós (Cri5002).

Neste ponto, é possível apontar para a necessidade de formação de professoresautores que, a partir do domínio do processo criativo, possam influenciar seu contexto através do estabelecimento de processos comunicacionais e colaborativos e da criação de conteúdos próprios em uma dinâmica colaborativa de construção, envolvendo os diferentes nós da malha ensino-aprendizagem e com o poder de romper com a lógica mass media freqüentemente impressa nas concepções e manifestações de informática educativa.

\section{Algumas considerações finais}

A partir da experiência realizada, foi possível perceber que a questão do Software Livre vai além da opção por não utilizar softwares proprietários na medida em que tem a ver com o rompimento com a dependência e com a reprodução, demandando uma postura ativa baseada em processos de autoria colaborativa, na ação-reflexiva e na construção permanente de competência de manutenção de uma cultura de rede.

É importante ressaltar que, em se reconhecendo a complexidade inerente ao desenvolvimento cultural do ser humano e dos grupos sociais a que pertencem, bem como a existência de Culturas que se imbricam, se auto-influenciam e são determinadas

\footnotetext{
5 Esta sigla identifica o fragmento do texto retirado do Banco de Dados da pesquisa armazenado no Sistema de Indexação e Tratamento de Dados (http://inf.upf.br/ imersao/stid2006). As três primeiras letras representam o nome do sujeito, os dois algarismos seguintes a Unidade de Dados - UD no banco e os dois últimos, 0 parágrafo correspondente dentro da UD.

V. $4 \mathrm{~N}^{\circ} 1$, Julho, 2006
} 
por um conjunto de elementos essencialmente ligados à vivência de cada indivíduo, era esperado que a construção da cultura de redes conceitualmente definida neste artigo, ocorresse de forma e em intensidades diferentes entre os participantes do projeto, o que de fato aconteceu.

Assim, a partir da análise feita à luz da filosofia do Software Livre, é possível afirmar que o processo vivenciado fomentou o desenvolvimento de cultura de rede nos envolvidos, sendo fundamental que se reconheça e reafirme a insuficiência deste na criação e no desenvolvimento desta cultura em toda a amplitude do conceito proposto, uma vez que pressupõe um amplo e profundo processo de discussão e, principalmente de ações que, considerando a horizontalidade das redes, envolvam Poder Público, Universidade e Escola.

Finalmente, e contextualizando ao momento político-social brasileiro, onde a opção pela utilização de Software Livre em estabelecimentos públicos e escolares deve representar muito mais do que uma escolha técnica e economicamente viável, mas, sobretudo uma forma de incentivar a inteligência coletiva e a criatividade, aponta-se para a necessidade de readequar os processos de formação docente em uma perspectiva de criação de cultura, revitalizada pela lógica das redes e baseada no uso e na filosofia do Software Livre, a fim de que possam auxiliar na vivência de uma informática educativa que valorize e respeite as diferenças num movimento de fortalecimento cultural dos indivíduos e grupos e de fomento ao desenvolvimento desta cultura de rede, fundamental ao cidadão contemporâneo.

\section{Agradecimentos}

À Universidade de Passo Fundo e à Universidade Federal do Rio Grande do Sul enquanto instituições de formação acadêmica e científica do pesquisador, à Fundação de Amparo à Pesquisa do Rio Grande do Sul pelo financiamento de bolsista de iniciação científica, ao Laboratório de Tecnologias Audiovisuais da Universidade de Roma Tre/Itália pela possibilidade de realização de estudos avançados na área de pesquisa e ao Alßan Office pelo apoio para a realização destes estudos através de Programa de bolsas de alto nível da União Européia para América Latina (bolsa nº E04D047495BR).

\section{Referências}

LEMOS, André. (2002) Cibercultura: Tecnologia e vida social na cultura contemporânea. Porto Alegre : Sulina.

LEMOS, André; CUNHA; Paulo. (2003) Olhares sobre a Cibercultura. Porto Alegre : Sulina.

LEMOS, André. (2004) Cibercultura, Cultura e Identidade: Em direção a uma "Cultura Copyleft"? In: Fórum Cultural Mundial e no Simpósio Emoção Art. Ficial (Itaú Cultural). São Paulo.

Cibercultura e Mobilidade: a Era da Conexão. in Razón y Palabra, n.

41, Octubre/Noviembre 2004. México. Disponível em http://www.cem.itesm.mx/dacs/publicaciones/logos/anteriores/n41/alemos.html : Acesso em março de 2005.

LÉVY, Pierre. As tecnologias da inteligência. O futuro do pensamento na era da informática. Rio de Janeiro: Editora 34, 1993.

MARASCHIN, Cleci. (2000) Tecnologia e exercício da função de autor. In: VII Seminário Internacional de alfabetização \& educação cientifica. Ijui: Ed. UNIJUI. 
PSL Brasil. O que é Software Livre. Disponível em http://www.softwarelivre.org/whatisit.php : Acesso em março 2005.

SANTOS, Milton. (2004) Por uma outra Globalização - do pensamento único à consciência universal. São Paulo, Record.

SILVEIRA, Sergio Amadeu da; CASSIANO, João. (2003) Software Livre e Inclusão Digital. Porto Alegre: Conrad.

\section{Bibliografia}

TEIXEIRA, Adriano Canabarro; BRANDÃO, Edemilson Jorge Ramos. (2003) Software Educacional: O difícil começo. Renote Revista Novas Tecnologias na Educação, v. 1, n. 1, 2003.

TEIXEIRA, Adriano Canabarro; FRANCO, Sérgio R. K.. (2004) Um Processo de Emersão Tecnológica com Vistas ao Domínio Crítico das Tecnologias por parte de Professores. In: XXIV Congresso da Sociedade Brasileira de Computação, 2004, Salvador. Anais do SBC 2004. Salvador - Ba: Sociedade Brasileira de Computação. . (2005) O projeto de Emersão Tecnológica de Professores como experiência de inclusão digital. In: VII Simpósio Internacional de Informática Educativa, 2005, Leiria, Portugal. Anais do SIIE 2005. 